Bentham OPen The Open Civil Engineering Journal

EDITORIAL

\title{
Open Challenges in Seismic Design of New Structures and Vulnerability Reduction of Existing Buildings
}

The Special Issue of The Open Civil Engineering Journal entitled "Open challenges in seismic design of new structures and vulnerability reduction of existing buildings" provides an insight into the most up-to-date techniques used at academic and professional level to perform advanced structural analyses of structures in medium/high seismicity zones.

Experience of past earthquakes has demonstrated that many common buildings and typical methods of construction usually lack basic resistance against earthquake actions, being mainly conceived to withstand only gravity loads. Open challenges to tackle a consistent seismic design are more profoundly faced by developing countries, were the inadequacy and poor access to advanced technologies, resources and knowledge lead to build new structures still vulnerable for horizontal loads. Conversely, open issues in industrialized countries like USA, EU and Japan are still the mitigation of the seismic vulnerability of the existing/historical built stock, almost always constituted by non-ductile materials and without any seismic preservation concept in the design. The special issue aims at comprehensively collecting papers dealing with the important issues related to a correct design of new structures and the vulnerability reduction of existing buildings in earthquake prone areas exhibiting insufficient load carrying capacity in case of seismic excitation.

The special issue collects ten contributions on structures made by both traditional R.C. and masonry, strengthening of existing structures with innovative materials, isolation systems as well as emblematic case studies.

A good balance among advanced computations on case studies, design considerations as well as strengthening proposals for vulnerability reduction is worth noting. It is in particular remarkable the utilization of non-standard numerical tools for complex case-studies, where new approaches for the interpretation of the seismic behavior of structures in presence of different kinds of non-linearity are presented. It is noticeable the constant effort to put the knowledge beyond the existing state-of-the art, moving on the cutting edge research in the field.

In [1], Habieb and co-workers present an advanced numerical approach to analyze a newly conceived low cost frictional seismic base-isolation system for residential buildings in developing countries.

Capozucca, Magagnini and Pace in [2] discuss a FE model for an experimented brickwork masonry building under eccentric shear force.

Tiberti and Milani in [3] have an insight into the damages suffered by an historical city center (Finale Emilia) after the 2012 Emilia Romagna sequence.

Clementi and co-workers in [4] discuss the vulnerability of cultural heritage structures, with reference to a church embedded into a built aggregate.

Formisano et al., in [5] deal with a still under-investigated topic, namely the damage speedy estimation of entire urban sectors, focusing on a case study in San Potito Sannitico, southern Italy.

Paper [6] is devoted to the analysis of the seismic vulnerability (where fragility curves are provided) of existing Italian industrial steel buildings.

Mezzapelle et al., in [7] discuss the importance of dowel-pin connections on the seismic fragility assessment of RC precast industrial buildings. 
Paper [8] shows the seismic response of a half scale three-story infilled RC building strengthened with FRP, both from an experimental and numerical standpoint.

Vassilopoulou et al., [9] provide practical criteria for a preliminary design of an arched steel bridge on shallow foundation under soil liquefaction conditions, whereas Laterza et al., in [10] analyze the seismic performance of a multi-span existing masonry arch bridge.

We would like finally to thank all the authors for their valuable contributions. All manuscripts underwent technical peer review. We therefore also wish to thank all the reviewers for their critical comments which undoubtedly improved the original technical value of all contributions.

\section{REFERENCES}

[1] A.B. Habieb, and G. Milani, "Low cost frictional seismic base-isolation of residential new masonry buildings in developing countries: A small masonry house case study", Open Civil Eng. J., vol. 11, pp. 1026-1035, 2017.

[2] R. Capozucca, E. Magagnini, and G. Pace, "FE modelling of experimental brickwork masonry building under eccentric shear force", Open Civil Eng. J., vol. 11, pp. 1036-1058, 2017.

[3] S. Tiberti, and G. Milani, "Historic city centers after destructive seismic events, the case of Finale Emilia during the 2012 Emilia-Romagna earthquake: advanced numerical modelling on four case studies", Open Civil Eng. J., vol. 11, pp. 1059-1078, 2017.

[4] F. Clementi, E. Quagliarini, F. Monni, E. Giordano, and S. Lenci, "Cultural heritage and earthquake: The case study of "Santa Maria della Carità" in Ascoli Piceno", Open Civil Eng. J., vol. 11, pp. 1079-1105, 2017.

[5] A. Formisano, N. Chieffo, and M. Mosoarca, "Seismic vulnerability and damage speedy estimation of an urban sector within the municipality of San Potito Sannitico Caserta, Italy", Open Civil Eng. J., vol. 11, pp. 1106-1121, 2017.

[6] A. Formisano, I. Iannuzzi, G. Di Lorenzo, and R. Landolfo, "Seismic vulnerability and fragility of existing Italian industrial steel buildings", Open Civil Eng. J., vol. 11, pp. 1122-1137, 2017.

[7] P.A. Mezzapelle, A. Scalbi, F. Clementi, and S. Lenci, "On the influence of dowel-pin connections on the seismic fragility assessment of RC precast industrial buildings", Open Civil Eng. J., vol. 11, pp. 1138-1157, 2017.

[8] F. Bianchi, R. Nascimbene, and A. Pavese, "Experimental vs. numerical simulations: seismic response of a half scale three-storey infilled RC building strengthened using FRP retrofit", Open Civil Eng. J., vol. 11, pp. 1158-1169, 2017.

[9] I. Vassilopoulou, V. Kaymenaki, C.J. Gantes, and G. Bouckovalas, "Criteria for preliminary design of an arched steel bridge on shallow foundation under soil liquefaction conditions", Open Civil Eng. J., vol. 11, pp. 1170-1190, 2017.

[10] M. Laterza, M. D’Amato, and V.M. Casamassima, "Seismic performance evaluation of a multi-span existing masonry arch bridge", Open Civil Eng. J., vol. 11, pp. 1171-1207, 2017. [http://dx.doi.org/10.1063/1.4992619]

Gabriele Milani

Technical University of Milan, Piazza Leonardo da Vinci 32 Milan, Italy

E-mail: gabriele.milani77@gmail.com

Antonio Formisano

University of Naples Federico II

Piazzale Tecchio 80

Naples, Italy

Francesco Clementi

Università Politecnica delle Marche

Via Brecce Bianche 12

Ancona, Italy

This is an open access article distributed under the terms of the Creative Commons Attribution 4.0 International Public License (CC-BY 4.0), a copy of which is available at: https://creativecommons.org/licenses/by/4.0/legalcode. This license permits unrestricted use, distribution, and reproduction in any medium, provided the original author and source are credited. 